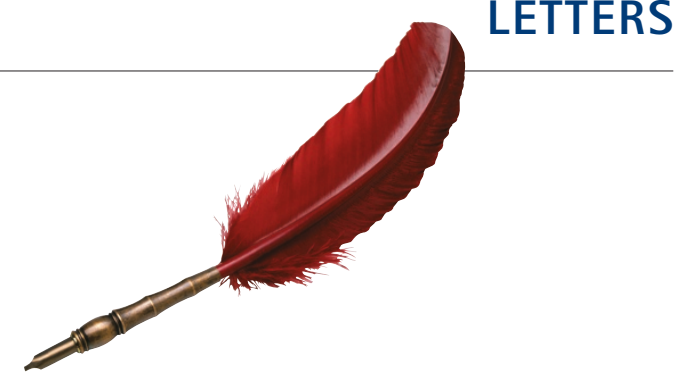

\section{Student debt dilemma}

Sir, further to the letter by T. Idrees and U. Qureshi (BDJ 2004, 196: 248) it is refreshing to see that two aspiring dentists have raised this important issue that appears to have been sidelined for too long. If I may, I would like to add another angle to this topic.

As our representative professional body, I would be grateful if someone could highlight the following. Firstly what has the BDA done to improve the spiralling debts of the average dental undergraduate and further, what is the BDA doing to improve the situation financially for those dentists wishing to pursue postgraduate studies thus ultimately to the benefit of the patients?

As a young dentist in London, I graduated with $£ 18,000$ worth of debt and that naturally has deterred me from pursuing a career in postgraduate dentistry. I would urge more members to speak up against this problem and moreover, encourage the BDA to speak up more.

\section{W. H. Fazel}

By email

Sara Osborne, Director of Professional Services at the BDA responds:

I would like to thank Dr Fazel for raising

\section{Conscious sedation}

Sir, I read the opinion article comparing conscious sedation and general anaesthesia (GA) (BDJ 2004, 196: 133) with interest as a dentist working as part of a team treating paediatric dental patients under GA. Since many dentists today do not practise in this field, I am worried that the "hypothetical case description of treatment under GA' in Israel might be confused with practice in the UK today. I would be most grateful if you would be so kind as to publish a description of paediatric GA as practised in Torbay.

Mike, a three-year-old, fourth child of a single mother is very unco-operative. He has had toothache for several weeks, but it is only because he kept his mother up all this topic which is obviously of concern to those involved and to the BDA. I can assure him that the BDA has been working to raise the profile of the student debt problems and has undertaken extensive survey work over a number of years. This information has enabled the Association to highlight the impact of this issue, for example, on career choices. We take this subject very seriously, and have also responded to the Department of Education and Skills White Paper on 'Widening Participation in Higher Education' to support the reintroduction of maintenance grants, combined with a system of scholarships. A further consultation is now taking place and the $B D A$ will take the opportunity to raise this matter again.

With regard to Dr Fazel's second point on improving the financial situation for those undertaking postgraduate studies, the BDA has submitted evidence to the Doctors and Dentists Review Body relating to the additional value of the skills of dentists with additional qualifications and experience but these arguments have not been supported by the Health Departments. This is a difficult area, but I can assure you that we will not let the matter rest. doi: 10.1038/sj.bdj.4811361

night that she has brought him to the Community Dental Clinic. This is his first visit to a dentist. Mike is coaxed into a 'mirror only exam' on his mother's lap. He has class 2 lesions in all his deciduous molars, his upper Ds are decayed to the cervical margin and both are abscessed.

After a discussion with his mother about the treatment alternatives under GA and LA and the relative risks, it is agreed we undertake a clearance of the deciduous molars under GA. The patient and his mother are shown how Mike will be anaesthetised and the whole procedure explained. An appointment is made at the family's convenience and an effort is made to ensure that Mike will be treated by the team he already knows. Mike is prescribed antibiotics and pain relief.
Ten days later Mike is admitted at the day surgery unit of the hospital. He can play in the separate children's play area or watch TV. He is greeted by the dental nurse, taken to a private office and weighed. His dentist confirms consent and he is examined on his mother's lap by a consultant anaesthetist. If it is considered necessary an oral sedative is administered in an orange drink.

Mike is led down a corridor, decorated with Beatrix Potter pictures, by his mother. Still wearing his ordinary clothes, he enters the magnolia painted theatre with nursery rhymes on the walls. Mike sits on his mother's lap, who is encouraged to cuddle him and hold his hands. The anaesthetist tells and shows Mike what he is going to do. Then he holds the tube of the anaesthetic machine close to the patient's nose, allowing Mike to inhale the anaesthetic. Mike drifts into unconsciousness. There is no hurry. After Mum has kissed him and is ready, Mike is lifted from her arms. His mother returns to the waiting room for a cup of tea or outside for a cigarette. Although his mother has left there is no need to rush, monitors are placed, but the team has to allow time for Mike to be sufficiently anaesthetised for his muscles to relax and so that he will not feel pain. Once he is fully anaesthetised a suppository is inserted for pain relief later. The back of his mouth is packed with a pre-formed sponge and his teeth extracted.

Once haemostasis is observed the sponge is removed and Mike is wheeled to recovery. His mother and several nurses are with him as he awakens, only half an hour after the start of the procedure. He is tearful, in pain and has a headache. After further pain relief, Mike is soon sitting up and watching cartoons on TV. He sips a glass of squash. An hour later Mike goes home. Mike's mother is phoned, either that afternoon or within 24 hours to establish that everything is OK. An appointment is made at the family's convenience to review the patient the following week. At review, which most patients attend, Mike is better able to manage an examination. Fluoride is applied to his remaining teeth 
and dietary advice is offered. Mike (and his siblings ) have the opportunity to attend for six monthly check ups. He can have regular fluoride applications and fissure sealants when he is older. But perhaps like many others in his social class his family will not give priority to dental care. I work with first class dental and anaesthetic colleagues, we are not the best in the world, but we are representative of caring Community Dentistry in the UK today.

\section{R. A. Baker \\ By email \\ doi: 10.1038/sj.bdj.4811362 \\ Do cycle helmets work?}

Sir, it was disappointing and somewhat confusing to see a photograph of a dentist with a motor racing driver promoting compulsory wearing of cycle helmets $(B D J$ 2004, 196: 445). The Cyclists Touring Club has drawn attention to the total lack of evidence of beneficial change in cyclist head injury rates or severity in countries that have made helmet wearing compulsory. Indeed in some cases the figures have got worse. Cycling in the UK is considerably safer than driving in France, even if it does not necessarily feel that way. So why is our motor racing friend not promoting the wearing of driving helmets? Think of the head injuries prevented, not to mention feeling how David Coulthard feels in his car.

\section{Y. Maidment}

By email

doi: 10.1038/sj.bdj.4811363

\section{Digitally aware dentists}

Sir, you are correct in your assumption that dentists are less digitally aware than their patients (BDJ 2004, 196: 309). Whilst the profession is way behind them in the use of electronic communications it is important to understand the reasons and find rapid solutions. There is presently no chance of the Government target of April 2005 being met with NHSNet(N3)connections for all PDS Providers as part of their new contract. The requirements are demanding with certification and conditions of use having to be fulfilled. The introduction and use of computers in dentistry has a rather unhappy history being littered with tales of expensive exploitation and technical failures. With obsolescence, hardware/software problems, expensive technical support, viruses and numerous other problems rife can you really blame those who are happier standing on the touchlines? How do spectators join the electronic players and how can they embrace the new electronic era with confidence and trust? For those of us who have access to a technical team and electronic communications as part of our daily business lives it is easy to take the benefits for granted and keep abreast of the latest advances. But for many others with little or no background or experience of computers, the prospects of utilising electronic messaging solutions are daunting. There are also the additional burdens of patient confidentiality and EEC guidelines restricting the use of electronic communications by the regulated professions.

Yes, more and more people are using the internet to access dental practice web sites to learn more about professional fees, specialist services and electronic appointment booking facilities. Digitally aware dentists are exploiting the benefits of internet marketing and advertising to attract high value new patients in the technologically aware age group of 30-45 years of age. I believe that an approved national course of education and training is going to be crucial in closing the electronic gap between dentists and their patients and it will be a demanding agenda compressed into 12 months.

Whilst the BDA has a role to play so does the GDC and the new PCT's. It seems to me that the new PCT structure is well placed to investigate the extent of the problem and make arrangements to provide the necessary educational training at a local level without delay. Without this the NHS plans to modernise communications within the NHS will be in tatters where dentistry is concerned.

\section{N. J. Knott}

doi: 10.1038/sj.bdj.4811364

\section{Bug busting}

Sir, I read P D Copson's letter (BDJ 2004, 196: 248 ) with interest and have to agree that the problem of head lice is a headache for dentists. Various modern day treatments have little or no effect upon these small sturdy creatures, and can cause quite a violent reaction in those with sensitive skin. I have a very simple remedy though which I have used on my children when they have inadvertently carried these bugs home from school hair conditioner. This can be any brand as long as it is quite thick. After plastering over the head thickly and leaving for an hour, the use of a fine tooth nit comb before rinsing should root the culprits out after they have suffocated. Repeat during the week once or twice until the hair is clear and you need never be troubled again. We tend to keep up the treatment once a month and it really does work.

\section{S. Ekelund \\ London}

doi: 10.1038/sj.bdj.4811365 